\title{
Azimuthal expansion of high-latitude auroral arcs
}

\author{
V. V. Safargaleev ${ }^{1}$, A. E. Kozlovsky ${ }^{2,3}$, S. V. Osipenko ${ }^{1}$, and V. R. Tagirov ${ }^{1}$ \\ ${ }^{1}$ Polar Geophysical Institute, Apatity, 184200, Russia \\ ${ }^{2}$ Sodankylä Geophysical Observatory, Sodankylä, FIN-99600, Finland \\ ${ }^{3}$ Department of Physical Sciences, University of Oulu, Oulu, FIN-90014, Finland
}

Received: 8 February 2002 - Revised: 7 March 2003 - Accepted: 25 March 2003

\begin{abstract}
We used the TV auroral observations in Barentsburg $\left(78.05^{\circ} \mathrm{N} 14.12^{\circ} \mathrm{E}\right)$ in Spitsbergen archipelago, together with the data of the CUTLASS HF radars and the POLAR satellite images to study azimuthal (in the east-west direction) expansion of the high-latitude auroral arcs. It is shown that the east or west edge of the arc moved in the same direction as the convection flow, westward in the premidnight sector and eastward in the post-midnight sector. The velocity of arc expansion was of the order of $2.5 \mathrm{~km} / \mathrm{s}$, which is $2-3$ times larger than the convection velocity measured in the arc vicinity and 2-3 times smaller than the velocity of the bright patches propagating along the arc. The arc expanded from the active auroras seen from the POLAR satellite around midnight as a region of enhanced luminosity, which might be the auroral bulge or WTS. The pole- or equatorward drift of the arcs occurred at the velocity of the order of $100 \mathrm{~m} / \mathrm{s}$ that was close to the convection velocity in the same direction. These experimental results can be well explained in terms of the interchange (or flute) instability.
\end{abstract}

Key words. Ionosphere (plasma convection) - Magnetospheric physics (auroral phenomena; magnetospheric configuration and dynamics)

\section{Introduction}

Auroral arcs are observed in the ionosphere as narrow luminosity bands stretched along the azimuth. They are commonly regarded as visible manifestations of the complex processes occurring in the magnetosphere-ionosphere system. Thus, dynamics of the auroral arcs give us important information on the magnetospheric physics.

Our knowledge on the nature and dynamics of the auroral arcs was based mainly on the regular observations in the auroral zone, which is confined within a relatively narrow (of the order of $200-500 \mathrm{~km}$ width) band surrounding the pole at

Correspondence to: A. E. Kozlovsky

(Alexander.Kozlovsky@oulu.fi) $65^{\circ}-70^{\circ}$ MLAT. Another limitation is caused by low temporal resolution of the instruments used. However, those data have allowed one to identify the most important morphological features of the discrete auroras. For instance, the local time distribution of the arcs has resulted in the concept of the auroral oval (Feldstein and Starkov, 1967). The arc thickness is now regarded as an important test for the numerous theories of auroral arc formation (Borovsky, 1993). The poleward motion of the arcs is assumed to be a signature of the substorm expansion phase (Snyder and Akasofu, 1972), as well as an indicator of the reconnection on the magnetopause (Sandholt et el., 1990) or in the lobes (Moen et al., 1993).

When speaking about the arc dynamics, one implies mainly the behaviour of the arc already existing in the sky. Indeed, most studies concentrated on brightening and fading of the arcs, as well as its north-south displacement, whereas relatively small attention was paid to the process of the arc bearing. Although many theories of auroral arc generation have been proposed (Borovsky, 1993), practically none of them take into account how the arc appears in the sky. In particular, it is not clear whether the arc flares up as a whole or "flows" along azimuth with finite velocity, gradually appearing in the camera's field-of-view from the west or east horizon. The manner of the arc appearance depends on the arc generation mechanism. Thus, the arc expansion along its stretching should be studied because it can provide a new understanding of the mechanisms of the auroral arc formation.

Usually, velocity of the arc drifting in the south-north direction does not exceed $500 \mathrm{~m} / \mathrm{s}$ at the ionosphere level (Haerendel et al., 1993). Such a slow motion may still be observed with low-resolution instruments like ASC. But propagation of the luminosity along the east-west direction may be much faster. For instance, a typical value of the velocity of the bright patches propagating along the arc is of the order of $10 \mathrm{~km} / \mathrm{s}$ (Oguti, 1974; Opgenoorth et al., 1983). Investigation of these fast processes requires observations with high temporal resolution, which can be achieved using TV recording. In this paper we use TV observations to study azimuthal expansion of auroral arcs, that is the movement of the east or 


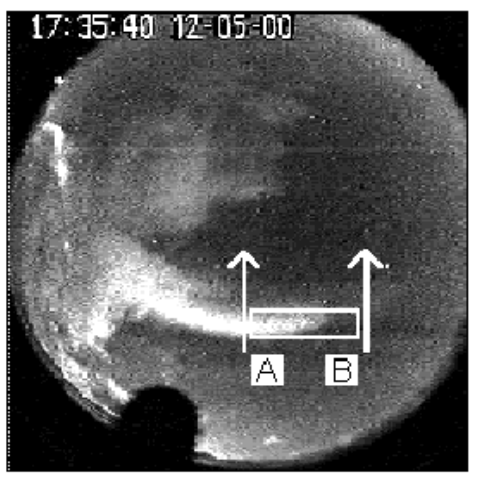

17:35:40 UT

05 December 2000
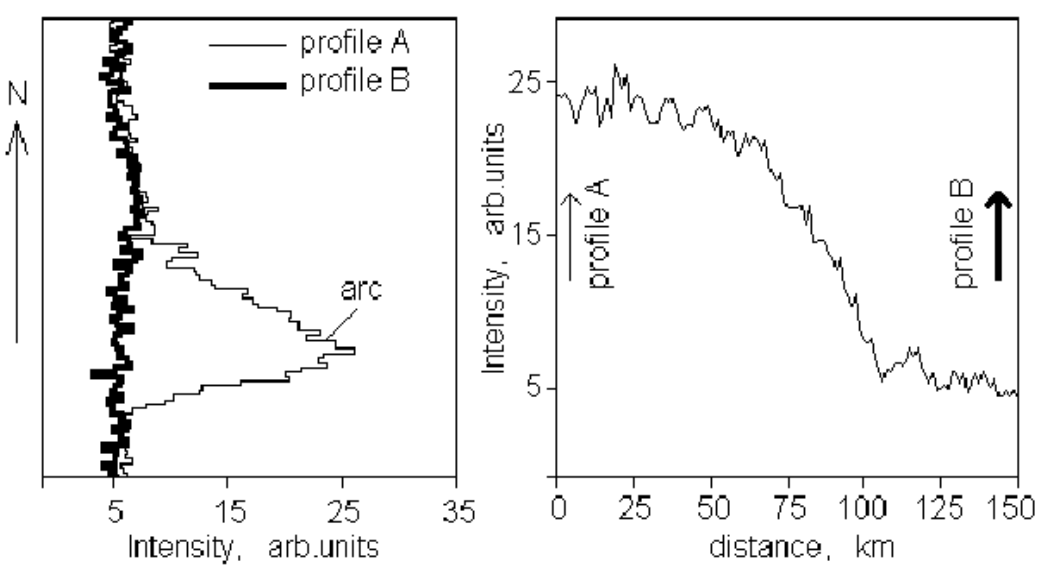

Fig. 1. An auroral arc edge observed above Barentsburg on 05 Dec 2000. Left panel: TV frame with profile A crossing the arc, profile B located west of the arc edge (white arrows) and horizontal strip oriented along the arc (white rectangle). Middle panel: intensity of the sky luminosity along the profiles A and B. Right panel: intensity of the sky luminosity between profiles A and B (along the horizontal strip).

west edges ("ends") of the arcs. We compare the azimuthal expansion of the arcs with the ionospheric plasma flows observed by CUTLASS HF radars and with the propagation of the bright patches along the arc. We also investigate the appearance of the arcs as related to the global auroral activity. The results are interpreted in terms of the mechanisms for the aurora formation.

\section{Instruments and methods of the investigation}

The main instrument of this study was the TV camera located in Barentsburg $\left(\mathrm{BAB}, 78.05^{\circ} \mathrm{N} 14.12^{\circ} \mathrm{E}\right.$; MLT $\approx \mathrm{UT}+$ $3 \mathrm{~h}$ ) in Spitsbergen archipelago, where the Polar Geophysical Institute (PGI) has resumed observations in November 2000. The TV camera was pointed towards the geographic zenith, where the fish-eye lens gave a circular field-of-view of $180^{\circ}$. Auroras were observed in the visible light. Global ultraviolet images from the POLAR satellite, the Defence Meteorological Satellite Program (DMSP) satellite data, and the keograms obtained from the ground-based all-sky cameras of the Finnish Meteorological Institute (FMI) were used to monitor auroral activity in the larger area around the BAB TV camera's field-of-view.

Ionospheric convection above Spitsbergen is observed by two HF-radars located in Hankasalmi (HANK) and Pykkvibaer (PYKK). The HF-radars are sensitive to F-region plasma density irregularities with scale sizes of $10-15 \mathrm{~m}$. At the F-region heights, such irregularities move with the convection velocity $(\boldsymbol{E} \times \boldsymbol{B} \mathrm{drift})$, so that the Doppler shift of the received signal gives the line-of-sight component of the convection velocity. Due to its geographical position, the PYKK radar is a suitable instrument for investigation of azimuthal plasma drift. But numerous gaps in its data forced us to use the HANK radar data, in which case the azimuthal component of the ionospheric convection velocity was derived from a single azimuth scan by using the "beam-swinging" method (algorithm of Ruohoniemi et al., 1989). Our data shows that this method gives a value close to the line-of-sight measurements.

The definition of the arc edge in optical data is explained in Fig. 1. Two vertical arrows and a horizontal rectangle in the TV frame indicate two profiles and the strip along which the intensity of luminosity was calculated (middle and right panels in Fig. 1). One can see that:

- An arc edge can be easily detected both in the TV frame (left panel) and in the right panel of the figure, where the mean value of the sky luminosity along the strip is shown;

- the arc intensity exceeds 20 units above the background level (profile A);

- the luminosity of the sky area west of the arc edge does not exceed 3 units above the background level, which is 8-10 times less than the arc intensity (profile B).

We used these qualitative and quantitative criteria for the arc edge definition. Note that the rather faint band of the diffuse luminosity that sometimes was seen east or west of the arc edge was assumed to be of another nature. The waveparticle interaction is a possible mechanism for the diffuse aurora, whereas brighter, discrete auroras are associated with the field-aligned acceleration in a region of upward fieldaligned current (Kamide and Rostoker, 1977; Swift, 1981).

Auroral dynamics can be clearly traced from the keograms made by extracting split-like fragments from individual frames and putting the fragments side by side. To study the aurora expansion in the east-west direction, we used three parallel (in pixel sense) splits with a central one passing through the zenith (centre in TV frame) and oriented along the meridian. We selected either the geographic or geomagnetic meridian for the central split orientation, depending on whether the arc was elongated along the geographic or geomagnetic latitude, respectively. Thus, expansion of the arc along its stretching in, for example, the westward direction 
would be manifested as an appearance of the arc edge at first in the east split, then in the central split, and finally in the west split. The expansion velocity can be determined from the propagation time of the edge between any two profiles (splits). To decrease errors, the side profiles were selected far away from the east and west borders of the frames, and the events were excluded from the analysis if the arc was far from the camera zenith to north or south. As a result, the main errors may be explained by the non-sharp edge of the arc (see Fig. 1, right panel, where the intensity of the arc luminosity falls up to the background level at the distance $\sim 50 \mathrm{~km}$ ) or (and) the erratic character of the arc expansion. As there are three possible combinations of the pairs of profiles, an average of the three velocities was regarded as the velocity of the azimuthal expansion of the arc. The velocity of the bright patches propagating along the arcs was calculated in a similar way.

\section{A case study: westward expansion of the arcs during a multiple arc event on 5 December 2000}

\subsection{Geomagnetic and auroral background}

For illustration, we selected the event for which data of all the instruments listed in the previous section were available. Figure 2 presents geomagnetic and optical background. In Fig. 2a, a magnetogram from the observations at Dixon Island (DIK, $73.54^{\circ} \mathrm{N} 80.56^{\circ} \mathrm{E}$; MLT $=\mathrm{UT}+5 \mathrm{~h}$ ) shows two negative bays of more than $250 \mathrm{nT}$ in intensity. At the same time, rather weak variations were observed at the high-latitude observations at Longyearbyen (LYR, $78.20^{\circ} \mathrm{N}$ $11.95^{\circ} \mathrm{E}$ ), located near BAB. Such a situation corresponds to a series of substorms that occurred close to midnight. The interval of interest is marked with an open arrow on the magnetograms and relates to a small negative excursion of the $H$-component, starting near 17:30 UT, which might be one more rather weak substorm onset. In this case, the aurora enhancement east from the observation point (Fig. 2b, top), in combination with faint luminosity seen equatorward, looks like an auroral bulge. The black circle on the POLAR images indicates the TV camera's field-of-view. The fragments of the DMSP satellite trajectories shown in the images will be discussed later.

\subsection{Velocity of the westward expansion of the aurora}

Development of the event in both space and time is shown in Fig. 3 as a sequence of TV frames. The upper series corresponds to the moment of the first arc appearance. Earlier, no auroras were seen in the sky. The west edge of the arc is clearly seen in all frames, indicating that the arc appeared from the east and expanded westward. Like the first one, the second arc appeared from the east (the middle series). By this time the first arc had shifted southward and its intensity decreased. The lower series shows that the first arc almost faded, the second arc followed the first one to the west and
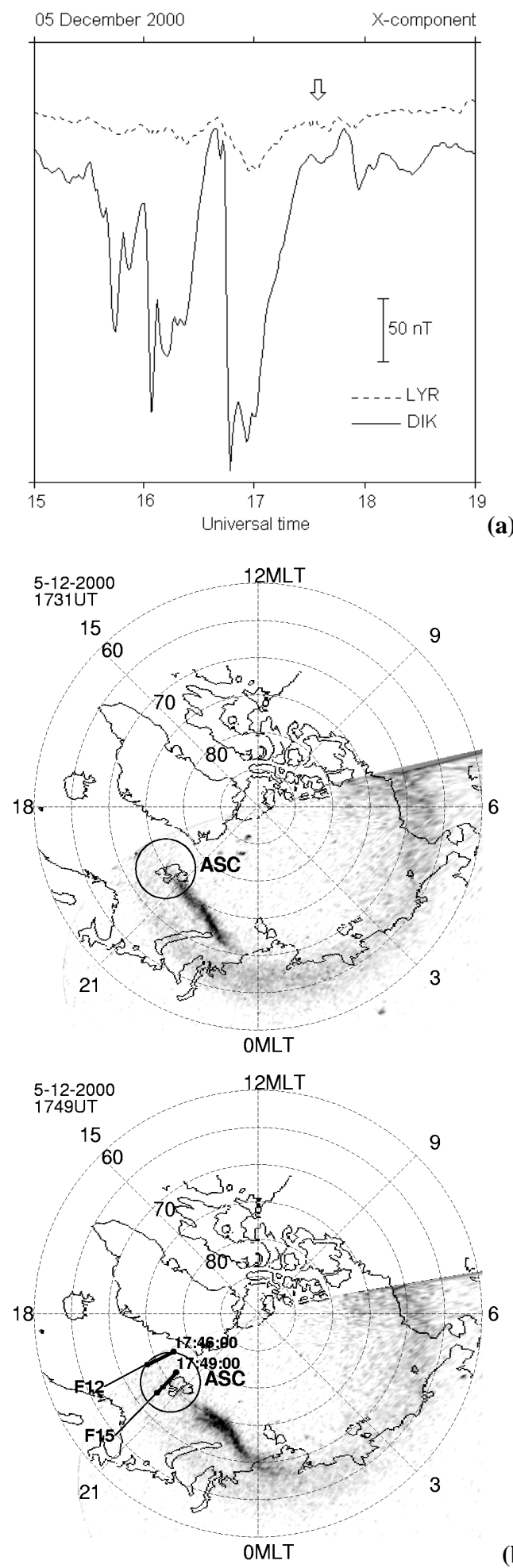

(b)

Fig. 2. Geomagnetic activity on DIK and LYR observatories (a) and POLAR images of the auroral oval showing the aurora development (b). Open arrow marks the interval of interest. Black circle indicates the BAB TV camera's field-of-view, bold lines correspond to the fragments of satellite DMSP trajectories, for which the particle data were analysed. 

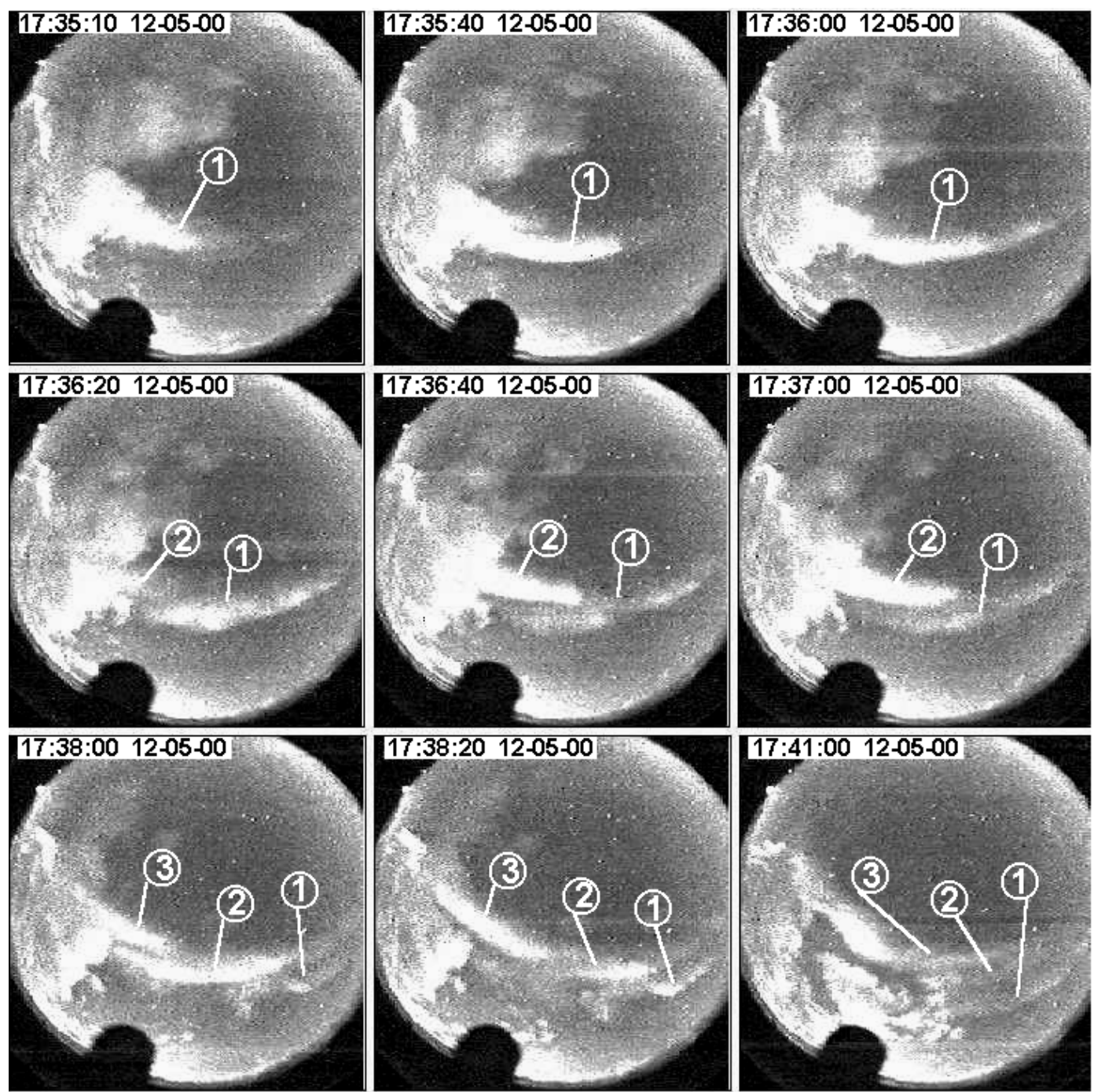

Fig. 3. The westward expansion of three auroral arcs during the multiple arc event on 05 Dec 2000. In each frame the geographic north and west are on top and on the right, respectively.

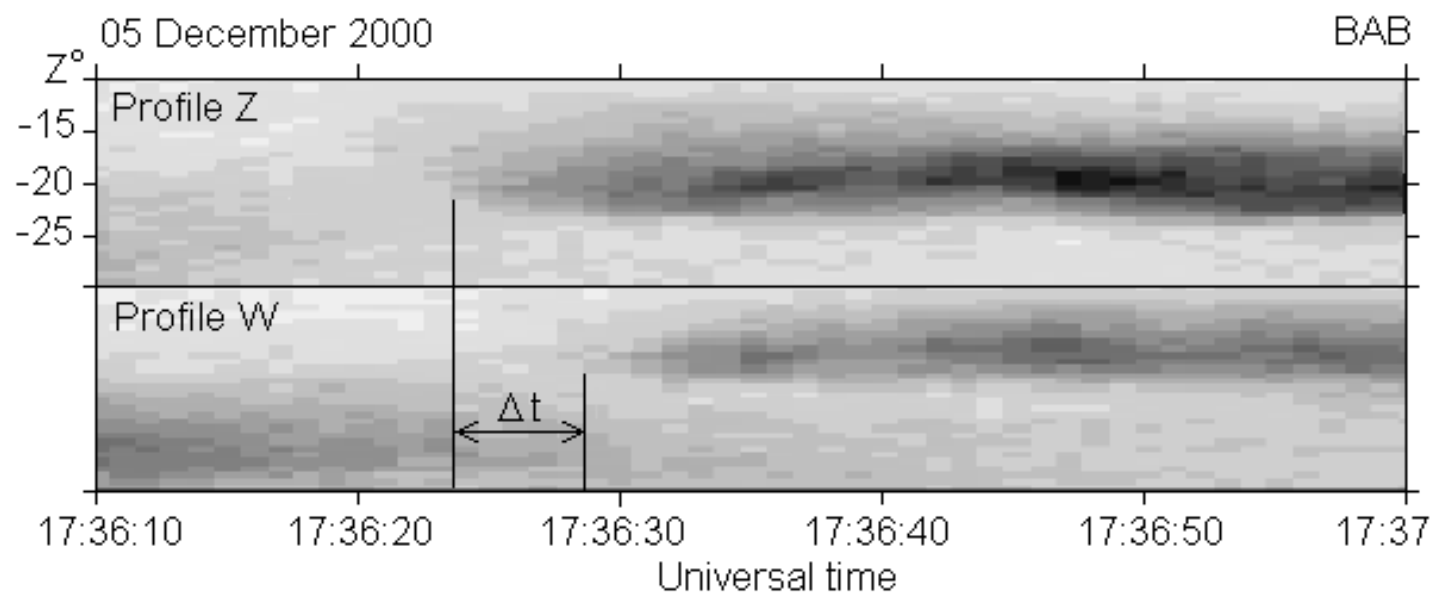

Fig. 4. Estimation of the propagation time of the arc edge from keograms. $Z^{\circ}$ means the zenith angle (positive to north). 
was also fading, and a new arc appeared from the east. During this time interval, the three arcs were seen in the sky simultaneously. Such an auroral configuration is often referred to as multiple arcs. Note also, that the direction of expansion of the arcs corresponds to the arcs as "flowing" from the area of enhanced luminosity seen in the POLAR images east of Spitsbergen (Fig. 2b).

Two keograms in Fig. 4 illustrate how the estimation of propagation time of the arc edge was done. The keogram indicated as "profile Z" shows the auroral dynamics along the geographic meridian crossing the zenith, so the vertical axis is labelled in zenith angles. The lower keogram was obtained along the split shifted westward at the distance of several pixels, which corresponds to $\sim 40 \mathrm{~km}$ at the ionosphere level near the zenith. In this example we used two of three profiles because of some nebulosity east of Barentsburg. The more intense auroras correspond to the more dark areas. The arc edge can be easily defined in both keograms as an enhancement of the aurora intensity. The propagation time of the edge from east to west, $\Delta t$, is a time delay between the aurora enhancement at $\mathrm{Z}$ and $\mathrm{W}$ profiles. The geographic location of the edge was calculated from the upper (zenith) keogram. Lower edge of the auroral luminosity was assumed at an altitude of $120 \mathrm{~km}$ (e.g. Starkov, 1968).

The upper keogram shows that the meridional (in the north-south direction) displacement of the arc was negligible. The arcs were stretched along about the geographic latitude, so that the measured velocities correspond to the velocities of the expansion of the arcs along their stretching. The first and second arcs expanded westward at a velocity of about $2000 \mathrm{~ms}^{-1}$. The third arc expanded westward two times slower.

3.3 Characteristics of the ionospheric convection in the vicinity of the arc

For the 1-min interval near 17:36 UT the values of the convection velocity measured by the both methods mentioned in Sect. 2 were available in several points inside the TV camera's field-of-view.

The spatial distribution of the line-of-sight velocity is presented in Fig. 5a. It is seen that poleward and equatorward of the BAB local zenith the ionospheric plasma moved away from the PYKK radar (red and yellow cells), whereas the blue cell just near the zenith indicates the drift in the opposite direction. In Fig. $5 b$ the convection velocity is shown as related to the auroral arcs presented in Fig. 3. Here, the mapping of the auroras into the geographic grid was performed for the TV frame taken at 17:36:40 (central frame in Fig. 3). Figure $5 b$ uses negative representation for the auroras, so that the arcs look like thin black bands. The moonhighlighted clouds covering the east-south part of the frame are not shown in the figure. North and south from the arcs, the convection appears to be away from the radar (the red and yellow arrows, respectively). Closer to the arcs, the plasma drifts toward the radar at the velocity $V_{\text {los }} \sim 1000 \mathrm{~ms}^{-1}$ (blue arrow). We can use this value to calculate the component
Pykk: vel

$173600 \mathrm{~s}$

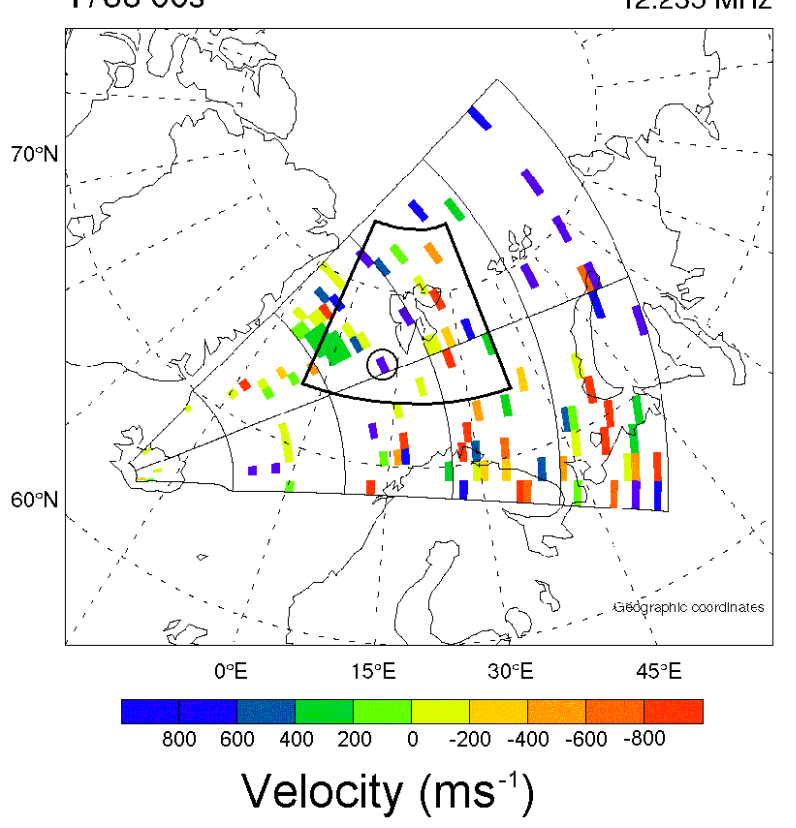

BAB: TV

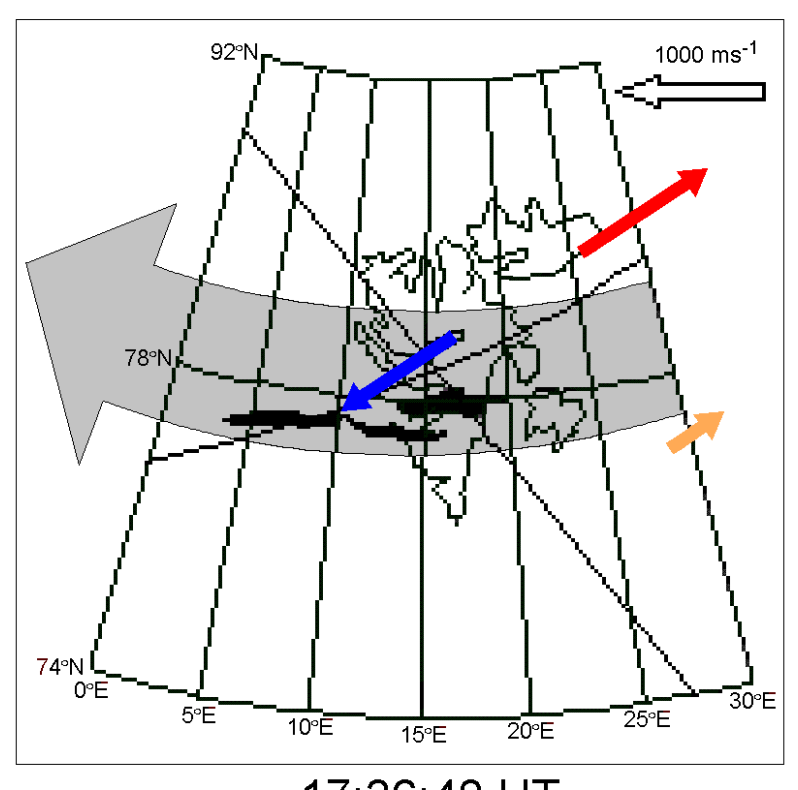

17:36:40 UT

Fig. 5. (a) the PYKK radar line-of-sight measurements. The positive values indicate motion toward the radar. (b) Ionospheric convection in the arc vicinity. Line-of-sight velocity is indicated with colour arrows. Also shown is the possible location and direction of fast plasma flow (gray arrow).

of the drift velocity along latitude, required for the observed line-of-sight velocity, through the relation $V_{\mathrm{los}}=V_{\text {arc }} \cos \theta$. Taking into account that in our case the angle between the 
Table 1. Characteristics of propagating events

\begin{tabular}{|c|c|c|c|c|c|c|c|c|c|c|}
\hline No. & Date & $\begin{array}{l}\text { UT } \\
\text { (hrs) }\end{array}$ & $\begin{array}{c}V_{\operatorname{arc}}(E) \\
\left(\mathrm{kms}^{-1}\right)\end{array}$ & $\begin{array}{l}V_{\mathrm{con}}(E) \\
\left(\mathrm{kms}^{-1}\right)\end{array}$ & $\begin{array}{l}V_{\operatorname{arc}}(N) \\
\left(\mathrm{ms}^{-1}\right)\end{array}$ & $\begin{array}{c}V_{\operatorname{con}}(N) \\
\left(\mathrm{ms}^{-1}\right)\end{array}$ & $\begin{array}{l}\text { Arc } \\
\text { lat }\end{array}$ & $\begin{array}{c}\text { Conv. } \\
\text { lat }\end{array}$ & $\begin{array}{c}\left|V_{\text {wave }}\right| \\
\left(\mathrm{kms}^{-1}\right)\end{array}$ & $\begin{array}{l}\text { Auroral } \\
\text { activity }\end{array}$ \\
\hline 1 & 2 & 3 & 4 & 5 & 6 & 7 & 8 & 9 & 10 & 11 \\
\hline 1 & 05.12 .00 & $17: 36$ & -2.0 & $-1.0 *$ & -100 & -210 & 77.8 & 78.7 & - & Polar \\
\hline 2 & & $17: 38$ & -1.3 & $-1.0 *$ & -50 & -180 & 78.0 & 78.2 & - & Polar \\
\hline 3 & 28.12 .00 & $16: 53$ & -0.4 & $-0.2 *$ & $\sim 0$ & - & 77.8 & 77.7 & - & - \\
\hline 4 & 19.01 .01 & $23: 32$ & 2.3 & $0.8^{*}$ & $\sim 0$ & - & 76.7 & 77.1 & 3.5 & - \\
\hline 5 & 05.12 .00 & 18:02 & -2.3 & -0.5 & $\sim 0$ & 100 & 76.7 & 75.1 & - & Polar \\
\hline 6 & 31.12 .00 & $00: 22$ & 2.3 & 0.9 & 100 & 160 & 76.5 & 76.1 & 3.5 & - \\
\hline 7 & 06.01 .01 & 02:00 & 2.4 & 0.5 & 100 & 200 & 77.8 & 77.4 & 5.5 & - \\
\hline 8 & 27.01 .01 & $02: 11$ & 2.6 & 1.6 & -200 & 90 & 77.1 & 75.7 & 3.6 & Polar \\
\hline 9 & 22.12 .00 & $16: 08$ & -1.5 & & -100 & & 76.7 & & - & - \\
\hline 10 & 29.12 .00 & $14: 44$ & -2.3 & & 150 & & 77.8 & & - & - \\
\hline 11 & & $14: 53$ & -2.3 & & $\sim 0$ & & 76.5 & & - & - \\
\hline 12 & & $17: 05$ & -1.0 & & $\sim 0$ & & 76.8 & & & Polar \\
\hline 13 & & $17: 17$ & -1.0 & & 100 & & 77.8 & & 2.0 & Polar \\
\hline 14 & 06.01 .01 & 03:08 & 1.6 & & -50 & & 76.7 & & 5.5 & F15 \\
\hline 15 & & 03:10 & 1.6 & & 50 & & 76.7 & & & \\
\hline 16 & 27.01 .01 & 02:46 & 2.3 & & 150 & & 77.8 & & 5.5 & ASC \\
\hline 17 & & 03:19 & 3.1 & & 60 & & 77.8 & & & F15 \\
\hline 18 & & $03: 23$ & 1.5 & & 400 & & 77.8 & & & \\
\hline 19 & 26.02 .01 & $02: 16$ & 0.8 & & -150 & & 77.9 & & 3.7 & ASC \\
\hline
\end{tabular}

radar beam and the arc $\theta \sim 30^{\circ}$, the relation yields $V_{\text {arc }} \sim$ $0.7-1.0 \mathrm{kms}^{-1}$, that is $\sim 2$ times smaller than the speed of the arc expansion.

We suggest that such a distribution of the plasma convection corresponded to the westward convection flow channel, within which the arcs appear expanding from the east to the west. (In Fig. 5b this flow channel is indicated as a large grey arrow.) A similar model was proposed by Kan et al. (1996) for the post-noon early evening sector auroras. The observed convection speed in the enhanced channel ranged from $\sim 0.5$ to $\sim 3 \mathrm{kms}^{-1}$ (Kan et al., 1996; Nilsson et al., 1997).

At the point marked with a black circle in Fig. 5a the azimuthal component of the convection velocity was both measured by PYKK radar (along the line-of-sight), and derived from the HANK data (using the "beam-swinging" algorithm of Ruohoniemi et al., 1989). The values obtained by these two methods are $1125 \mathrm{~ms}^{-1}$ and $1085 \mathrm{~ms}^{-1}$, respectively. This difference is remarkably small. In the cases when data from PYKK radar were not available, we used the azimuthal velocity component obtained by the algorithm of Ruohoniemi et al. (1989).

\subsection{Characteristics of the precipitating particles}

Two DMSP satellites crossed the TV camera's field-of-view in ten minutes after the ground-based observations reported above (Fig. 2b). Spectrograms of precipitating particles obtained from the satellite are shown in Fig. 6. The F15 satellite was within the TV camera's field-of-view for a few tens of seconds (Fig. 2b), however the clouds above the BAB hindered a detailed comparison of the precipitation data with the auroral distribution. Nevertheless, by analysing the spectrograms we can conclude the following:

1. The arc was associated with the most poleward region of precipitating electrons of the "inverted-U" shape.

2. The arc was located poleward of the main auroral oval at the distance increasing with longitude (or MLT) away from the auroral bulge. The poleward boundary of the main auroral oval was determined as b5e (Newell et al., 1996), and the distance from this boundary to the arc increased to the west, from $\sim 100$ to $\sim 200 \mathrm{~km}$ for MLT from $\sim 20: 30$ to $\sim 19: 40$, respectively.

3. The spectrum of precipitating electrons indicates that they underwent field-aligned acceleration.

4. The peak energy of the precipitating electrons decreased away from the bulge, from 1 to $0.6 \mathrm{kV}$ (for MLT from $\sim 20: 30$ to $\sim 19: 40$, respectively).

5. Three others "inverted-U" signatures suggest discrete auroras equatorward of the considered arc.

Items 2 and 4 allow us to suggest that the magnetospheric sources of the arc were associated with the narrow plasma tongue developing from the region of the bulge at a small angle to the plasma-sheet boundary associated with the poleward boundary of the main auroral oval. 


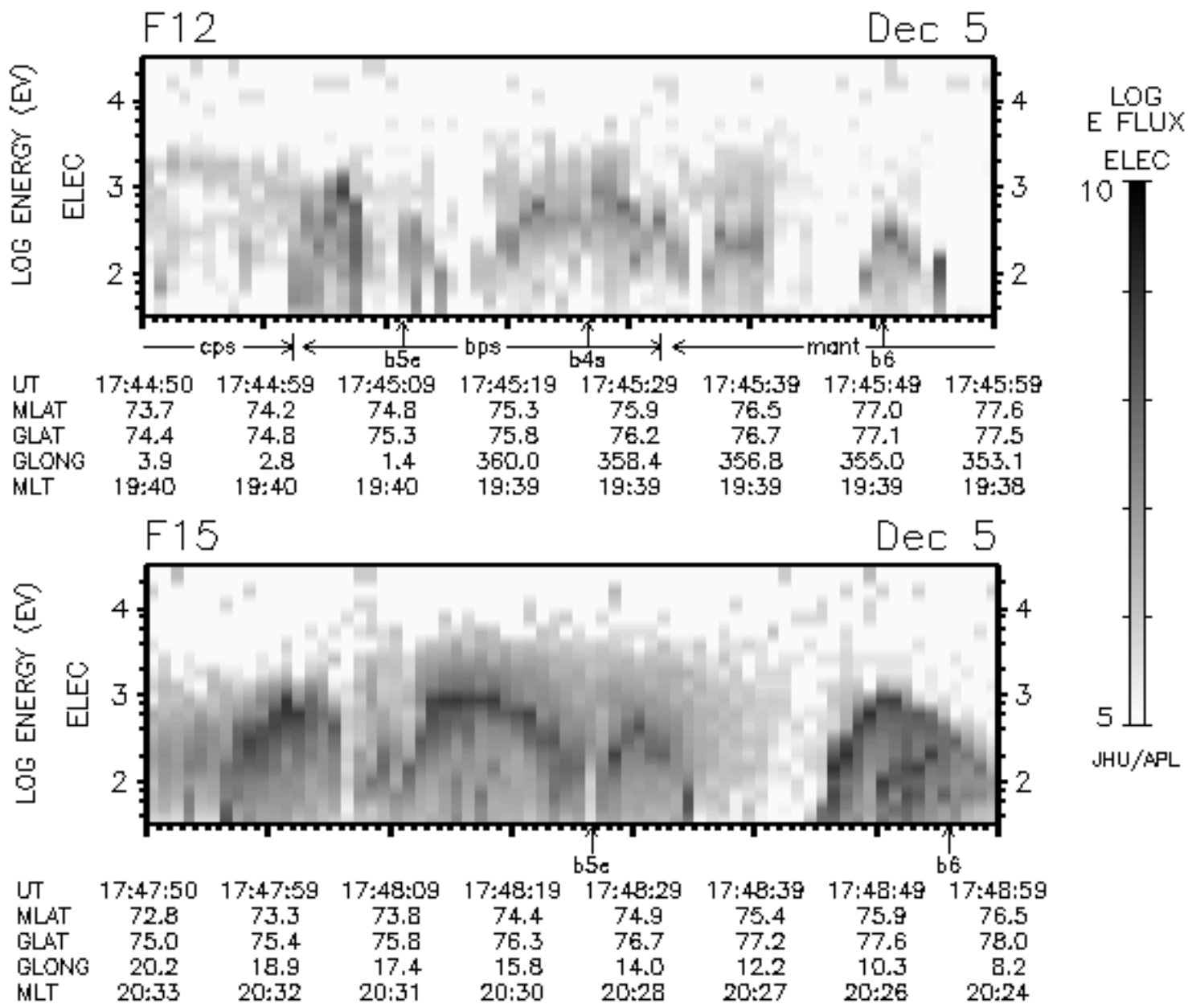

Fig. 6. Spectrograms along the fragments of satellite trajectories shown with bold lines in Fig. 2 b.

\section{Statistics}

Due to its geographic position, round-the-clock observations of auroras are possible in Barentsburg during the winter months. In our data, most of the dayside auroras were the rayed arcs that did not allow us to investigate their azimuthal expansion, both by naked eyes and the method described in Sect. 2. Rather homogeneous arcs might be observed in the night- and evening-side. But as a rule, the midnight auroras were located between the Scandinavian peninsula and Spitsbergen, so the arcs were seen from BAB at large zenith angles, which decreases the accuracy of the data analysis.

Among the nightside auroras reaching Barentsburg, there were many cases when the arc started as an enhancement of the pre-existing faint arc. However, for our analysis we selected the events when the pre-existing auroras were diffuse, and the intensity of the appearing arc exceeded the diffuse background by a factor of ten or more in the intensity. The diffuse and discrete auroras have a different nature, so that we regard the selected cases as an appearance of a new arc rather than as the brightening of the pre-existing one.

We left out of consideration the intervals of the high auroral activity occurring just above BAB. In such cases the auroral displays were very complicated and highly variable.

Thus, for our study we selected the cases (further referred to as expanding events) when the east- or westward moving edge of the high-latitude arc was identified clearly in the TV records. The optical data from nine winter nights were examined, and 19 propagating events have been selected. Due to the above-mentioned reasons, most of the events occurred in the evening pre-midnight and post-midnight morning sectors. Herewith, multiple arcs came to $~ 90 \%$ of the events selected. The results are summarised in Table 1. Dates of the events are placed in columns 2 and 3 . The velocity of the arc expansion along the east-west direction (positive to east) and the arc drift velocity in the south-north direction (positive to north) are indicated in the fourth and sixth columns, respectively. The components of the convection velocity are shown in columns 5 and 7. The $V_{\text {con }}(N)$ component was obtained from the HANK radar data. For the events 1-4 we inferred the $V_{\text {con }}(E)$ from the line-of-sight measurement, whereas for the next four events this component was calculated using the algorithm by Ruohoniemi et al. (1989). Latitudes of the arcs and the points of the convection measurements are presented in the eighth and ninth columns, respectively. The $\left|\mathrm{V}_{\text {wave }}\right|$ 


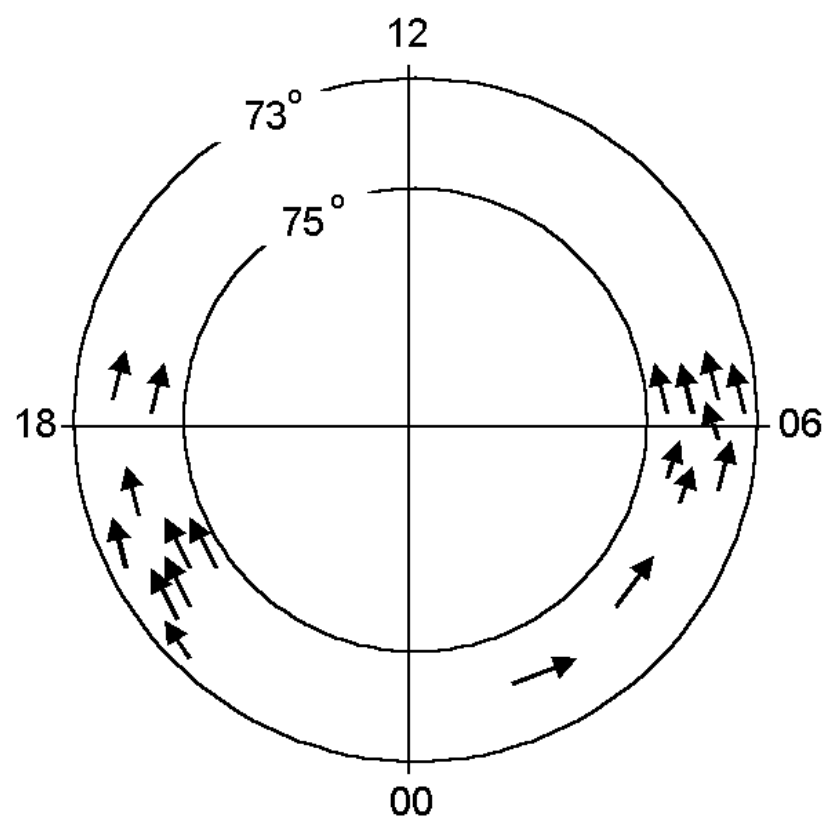

Fig. 7. Direction of azimuthal expansion of the high-latitude arcs as a function of local time.

is the velocity of bright patches propagating along the arc (column 10). In the last column, the instruments are listed that provided information on the larger scale auroral activity in the vicinity of BAB. The POLAR and DMSP satellites provided images of the auroral oval, and the all-sky cameras (ASC) of FMI displayed the auroral activity southward of Spitsbergen. All coordinates are geographic.

The diagram in Fig. 7 presents the considered events in the frame of MLT and geomagnetic latitude. Arrows indicate directions of the arc expansion along the azimuth. Figure 7 shows that the arcs propagate away from the local midnight, which corresponds to the eastward and westward arc expansions in the post- and pre-midnight sectors, respectively. Comparison with the POLAR and DMSP images has shown that the arcs propagated away from a localized area of enhanced luminosity (auroral bulge or WTS).

The ionospheric plasma flow data might be available from a large latitude range including the TV camera's field-ofview. However, the ionospheric disturbances associated with the auroral arcs caused problems for the radar measurements in the region adjacent to the arc. In particular, the plasma flow has not been studied in the regions between the multiple arcs. In addition, the auroral enhancement should cause reconfiguration of the local electric field via modification of the ionospheric conductivity in the arc vicinity, so that, in Table 1 we compare the arc motion to the convection measured at some distance from the arc (from 50 to $100 \mathrm{~km}$ as seen from columns 7 and 8 in the table), which means that we study the auroral dynamics in the frame of the background convection. In total, eight arcs have been observed simultaneously with the ionospheric convection. Figure 8a shows the velocity of the arc versus the ionospheric plasma veloc- ity measured in the arc vicinity. It allows us to conclude that the arcs expanded east- or westward in the same direction as the ionospheric plasma flowed. Velocity of the azimuthal expansion was of the order of $1-3 \mathrm{kms}^{-1}$, and the arc expansion was $1-2 \mathrm{kms}^{-1}$ faster than the convection velocity in the same direction. Note that in the PYKK radar data one might also see the convection reversal poleward or equatorward of the arc. In Table 1 these events are indicated with a “*” symbol.

Panel (b) in Fig. 8 demonstrates that the arcs drifted northor southward following the convection. The difference between the arc and convection velocities was within the order of $100 \mathrm{~m} / \mathrm{s}$ or less. The arcs tend to drift slower than the convection flow, but the velocity difference is of the same order as the uncertainty in the convection velocity derived from the radar measurements, that is $\sim 100 \mathrm{~m} / \mathrm{s}$ (Ruohoniemi et al., 1989).

Except of one case, the propagating events were observed during a substorm recovery. In some cases the auroras still remained active and small patches of enhanced luminosity were moving fast along the arc in various directions (see example in the Fig. 9). Velocity of the propagating patches is given in column 10 of Table 1 . In all cases the velocity of the patch was larger than the velocity of the arc edge.

In some cases the information about the auroral distribution outside the TV camera's field-of-view could be inferred from the POLAR or DMSP satellites and from all-sky cameras located in the north of the Scandinavian peninsula (column 11). These additional optical data showed the presence of auroras east or west, as well as south of the observational point. We interpret the former ones as the auroral bulge or WTS, whereas the auroras in the south horizon might be the "pre-existing" arcs, from which the auroral breakup had started and the WTS had developed.

\section{Discussion}

We examined several cases of the high-latitude nightside arcs observed mainly during the substorm recovery phase east or west of the nightside active region, like the WTS or auroral bulge. Below we formulate the results of our investigation in the order of their statistical reliability:

1. Our main finding is that these arcs expanded away from the midnight meridian and looked like they were originating from the WTS or auroral bulge. In the papers dealing with the substorm-associated auroras, at least three categories of discrete arcs observed in the vicinity of the WTS had been mentioned. Arcs from each category are characterised by a specific orientation (see Figs. 10 and 11). The first and second categories are the discrete auroras developing from pre-existing arcs during WTS formation. Away from the WTS, the arcs remain to be stretched along the latitude and they were classified as an auroral horn (Yahnin et al., 1983). At the front of the WTS, the pre-existing arcs are warping and becoming oriented along the meridian. Sometimes 

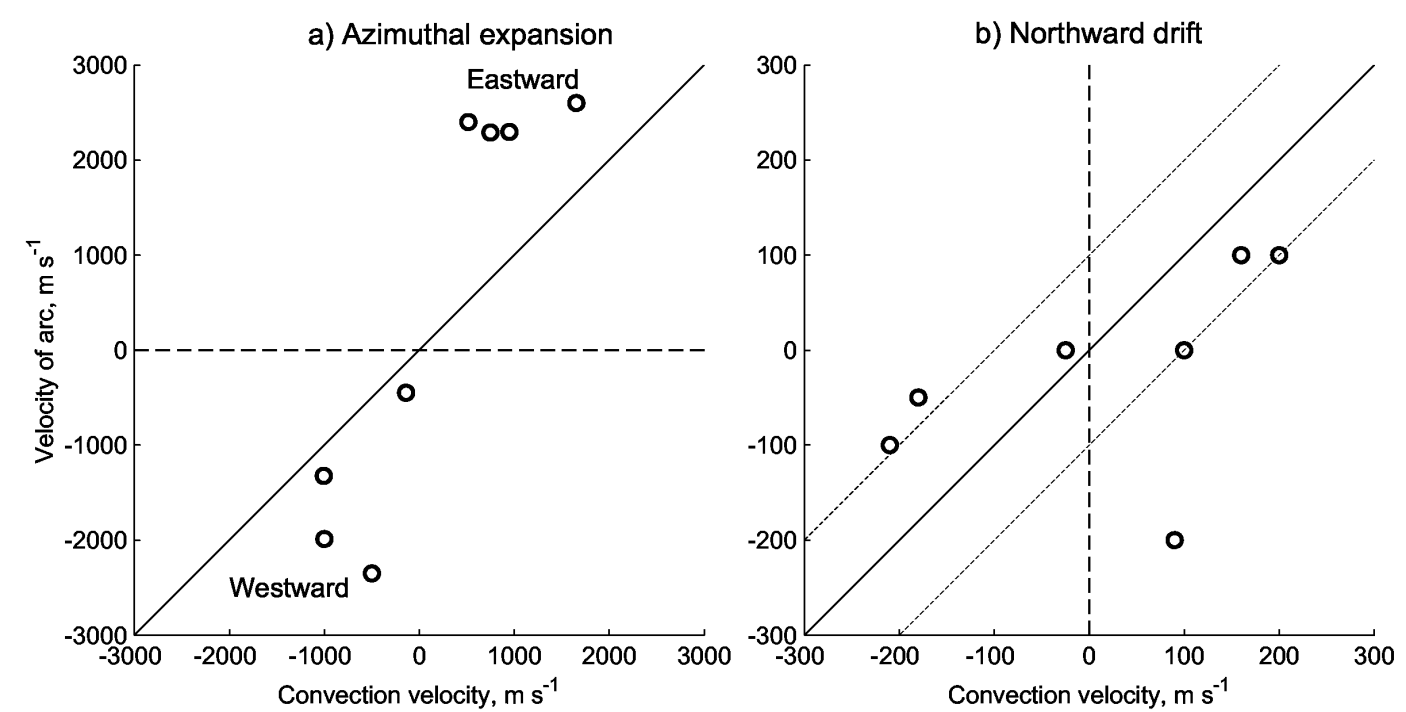

Fig. 8. Velocity of the arc versus the ionospheric plasma velocity measured in the arc vicinity. Solid line is bisector corresponding to equality of the two velocities.

these arcs are referred to as N-S structures (Rostoker et al., 1987). Arcs of the third category are connected with the equatorial part of the WTS, oriented along the bisector between the boundary of the auroral oval and the front of the WTS, and expand westward and poleward. Nielsen et al. (1993) reported a case of such multiple arcs observed by the Viking satellite.

The BAB TV camera, together with the all-sky cameras of the FMI and the instruments on board the Polar and DMSP satellites have allowed us to investigate the arcs in the context of large-scale auroral dynamics, including the WTS. The following three features inferred from those multi-instrument measurements allow us to conclude that we investigated the arcs of the third category.

(a) The orientation of all these arcs differed significantly from the $\mathrm{N}-\mathrm{S}$ orientation.

(b) In more than half of the expanding events the auroras were also seen southward of Barentsburg. We suggest that those arcs formed the auroral horn.

(c) In the case described in Sect. 3.4, the poleward boundary of the auroral oval and the arc demonstrated a divergence from 100 to $200 \mathrm{~km}$ when moving away from the WTS.

2. Our second finding is that the velocity of the arc expansion along the latitude was larger than the azimuthal component of convection velocity in the vicinity of the arc, but smaller than the velocity of the bright patches propagating along the arcs. Near the arc, the plasma flowed in the direction of the arc expansion, whereas no prevailing direction was found for the propagating bright patches. One should emphasise the difference between the two phenomena, i.e. the arc expansion along the east-west direction (see Fig. 3) and the patches propagating to the east or west along the existing arc (see example in Fig. 9). The auroral patches have been regarded as an ionospheric manifestation of the MHD waves propagating in the magnetosphere (see, for instance, Safargaleev and Osipenko, 2001; Danielides and Kozlovsky, 2003). Their velocity was of the order of several $\mathrm{km} / \mathrm{s}$, which is too high to be explained by actual plasma flows. On the other hand, the arc expansion manifests the "bearing" of the arc and, hence, should be considered in terms of mechanisms for the formation of fast plasma flows. Kan et al. (1996) suggested that such flows are the ionospheric traces of the closed magnetic lines convecting sunward in the magnetosphere, which can be driven by the dayside patchy-intermittent reconnection. However, Kan et al. (1996) did not discuss whether or not the reconnection might result in the generation of the arcs in the nightside, too. In our study the expanding events are connected with the substorm activity (namely with the development of the WTS or auroral bulge), so we suggest that the observed features of the high-latitude auroral arcs can be explained in terms of some substorm-associated instability that splits the convection flow. The low spatial resolution of the convection data did not allow us to perform a detailed analysis; however, sometimes the PYKK radar detected that plasma flows just near the arc were opposite to the flows observed north or south of the arcs. In the Table 1, these events are indicated with a "*" symbol. One event was discussed in Sect. 3.3. Such a convection pattern resembles the plasma motion under the interchange (or flute) instability.

3. One more important feature of the high-latitude arcs is that they drift north- or southward at the same velocity 


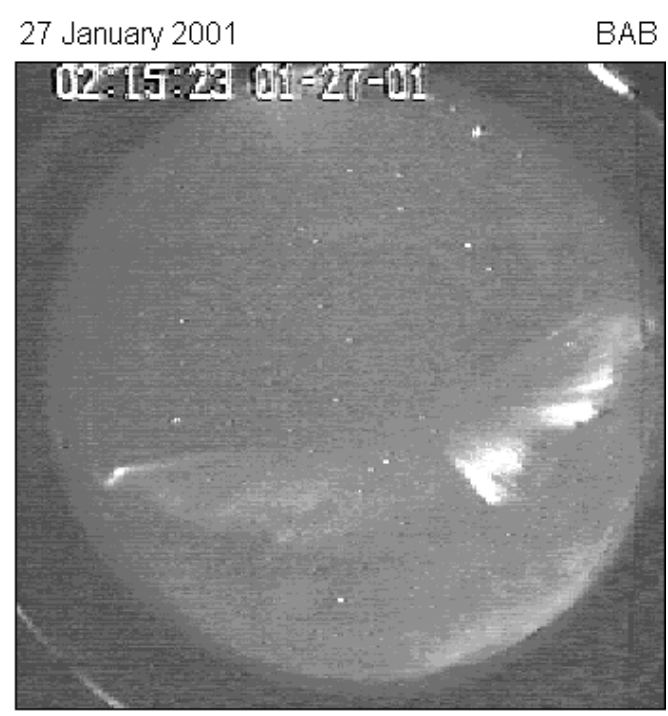

02:15:23 UT

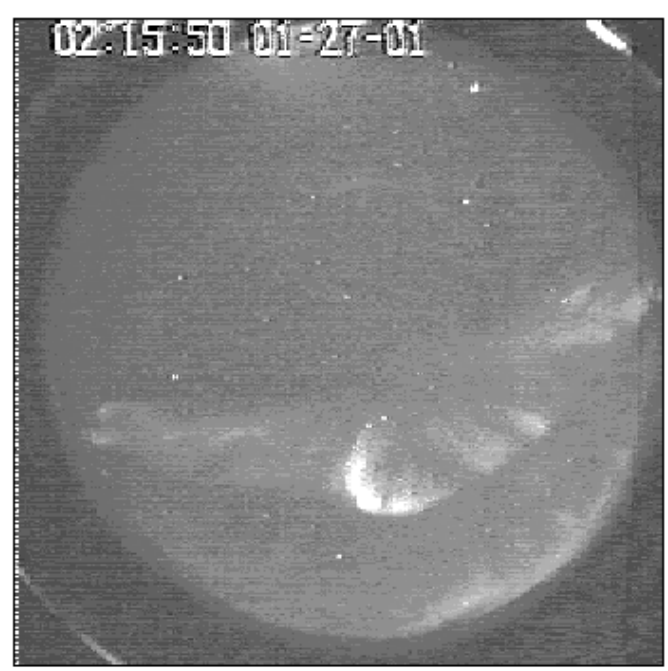

02:15:50 UT

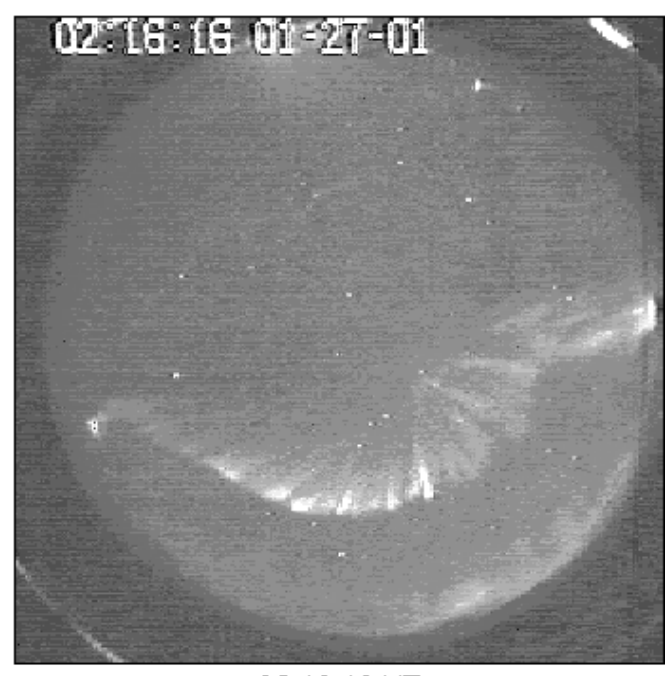

02:16:16 UT

Fig. 9. An example of the bright patches propagating along the arc before the arc intensification. as the ambient plasma. The relative motion of auroral arcs with respect to the magnetosphere-ionosphere convection is an important parameter which can help to select the proper mechanism for the arcs (Kozlovsky et al., 2001; Kozlovsky and Kangas, 2002). As we will discuss below, the arcs generated due to the interchange instability should drift across their stretching at the convection velocity.

On the basis of our observation, we can suggest that the highlatitude auroral arcs show the features that can be well explained in terms of the interchange (or flute) instability. The interchange instability may develop if

$\mathrm{d} P / \mathrm{d} U>\gamma P / U$,

where $U$ is the volume of the magnetic flux tube with unit magnetic flux, $P$ is the plasma pressure, and $\gamma$ is the adiabatic exponent (e.g. Kadomtsev, 1988). In accordance with Eq. (1), the outer boundary of any plasma volume is unstable if the magnetic field is curved. In this case the centrifugal force, $\boldsymbol{F}_{c}$, acting on the bouncing protons gives rise to the plasma irregularities along $\boldsymbol{F}_{c}$ which is the radial direction in the magnetosphere and $\mathrm{N}-\mathrm{S}$ direction in the ionospheric projection. Rezhenov (1995) regarded this instability as a possible reason for the $\theta$-aurora formation.

In accordance with Volkov and Maltsev (1986), condition (1) may also be satisfied in the near-Earth plasmasheet if the angle between $\nabla P$ and $\nabla U$ is non-zero, in which case the force $\boldsymbol{F}=\boldsymbol{F}_{c}+\nabla\left(P U^{\gamma}\right)$ gives rise to the structures with the wave vectors directed along $\boldsymbol{F}$ (along the bisector between $\nabla U$ and $\left.\nabla\left(P U^{\gamma}\right)\right)$. The development of the instability is illustrated in Fig.10 in the ionospheric projection. The force $\boldsymbol{F}$ (shown with a black arrow) causes the electrons and protons to move across the structures in opposite directions via the $\boldsymbol{F} \times \boldsymbol{B}$ drift (open arrow inside the structure), which results in the appearance of the positive and negative charges at the periphery of the structure. The charges generate the electric field $\boldsymbol{E}^{\prime}$, which causes further stretching of the structure via the $\boldsymbol{E}^{\prime} \times \boldsymbol{B}$ drift (open arrow at the end of the structure). Thus, the instability splits the plasma-sheet plasma and the magnetospheric convection into the multiple tongue-like jets of rapid plasma flow stretched at some angle to the $U=$ const lines. Between them, the plasma may drift in opposite direction. The electric fields propagate along the magnetic field lines to the magnetosphere forming the field-aligned current sheets at the edge of each plasma tongue: downward in the region of negative charge and upward at the opposite edge. The field-aligned currents can be associated with multiple auroral arcs. Finally, the distribution of the auroras will look like that shown in Fig. 11 or discussed by Nielsen et al. (1993).

Although the scheme in Fig. 10 agrees with the hypothesis of the multiple convection flow channels (Kan, 1996), the low spatial resolution of the radar data did not allow us either to confirm or confute this hypothesis. Figure 5a shows that the size of the measurement volumes (colour cells) is larger than the distance between the arcs, and the convection features might be interpreted as a single flow channel, 

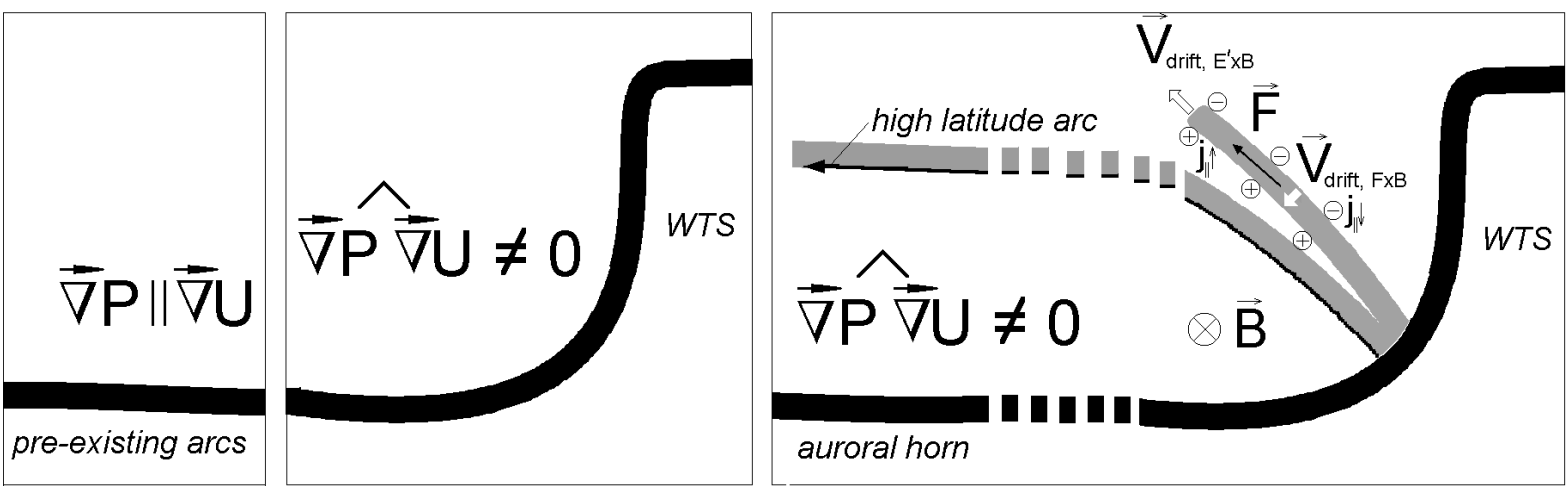

Fig. 10. (From left to right) development of the interchange instability in the vicinity of the WTS (see text for more detail). Auroras are black, plasma structures are grey.

only. Nilsson et al. (1997) discussed a single flow of the enhanced convection. Indeed, the interchange instability can yield a single plasma tongue (Rezhenov, 1995). Later, the single tongue can break down into multiple structures. In such a case, the aurora dynamics would be similar to those discussed in Sect. 3.2. The breaking of the tongue should occur at a large distance from the origin (WTS) and/or at the late (nonlinear) stage of the instability development.

A possible reason for the non-zero angle between $\nabla P$ and $\nabla U$ may be the local reconfiguration of the magnetosphere accompanying the formation of the auroral bulge. Another possible reason may be the following. In the magnetotail, $\nabla\left(P U^{\gamma}\right)$ is pointed away from the Earth (Borovsky et al., $1998)$ and $\nabla U$ is also away from the Earth. The pressure gradient can gain a normal component to $\nabla U$ due to the sunward convection in the plasma sheet, which is controlled by IMF $B_{z}$. (Volkov and Maltsev, 1986; Yamamoto et al., 1996). Also, the topology of the magnetospheric magnetic field (and, hence, $U$ ) depends on the solar wind pressure. Thus, variations of the interplanetary parameters may also control the instability growth rate through the global reconfiguration of the magnetosphere. Note that the mechanism by Kozlovsky and Lyatsky (1994) also gave rise to the N-S oriented auroral forms. Earlier, Lyatsky (1992) suggested the interchange instability for explanation of the WTS formation and substorm development. Thus, the auroral forms mentioned in the beginning of this section as category 2 and 3, as well as the WTS, may be explained by the similar mechanisms implying the interchange instability.

It is well known that the high conductive ionosphere suppresses development of the interchange instability through the "frozen-in" conditions for the magnetic field lines (Swift, 1967). However, the arc-associated parallel electric fields can decouple the magnetosphere from the ionosphere (Atkinson, 2001), which allows the instability to develop. On the other hand, the decoupling (associated with the field-aligned potential difference) can explain some of the difference between the ionospheric convection velocity and the aurora expansion associated with the motion of the magnetospheric plasma.

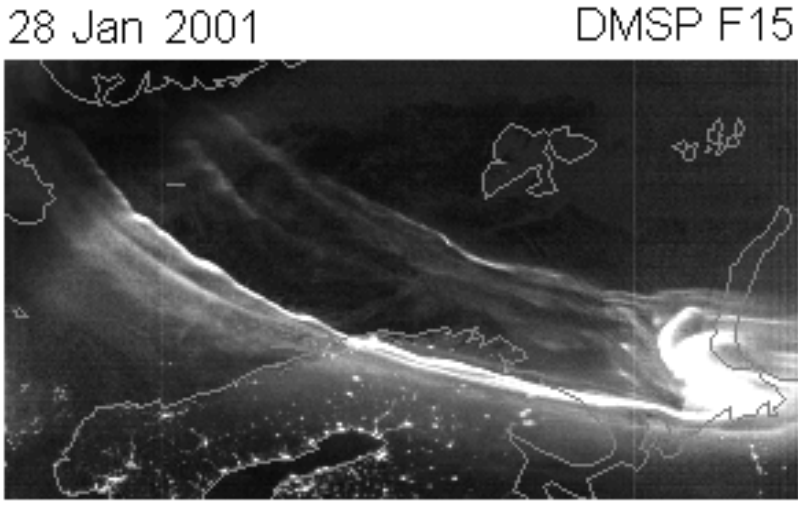

18:25 UT

Fig. 11. Aurora distribution as seen from the DMSP F15 satellite.

In light of the above physical background, we can suggest the following interpretations to our observations. The nightside large-scale auroral activity indicated the changes in the plasmasheet that created favourable conditions for the interchange instability. The instability produced the jets of faster sunward plasma flow originated from the active region. The high-latitude auroral arcs are the ionospheric signatures of the fast plasma-sheet flows, so that the plasma velocity in the arc region should be larger than the velocity measured by the radar equatorward of the arc. Moreover, the arc is associated with a field-aligned potential drop, so even inside the arc the ionospheric plasma flow can be slower than the plasma flow just above the acceleration region. The dispersion equation for the interchange instability suggests the wave velocity (i.e. the arc velocity across its stretching) to be equal to the convection velocity (Volkov and Maltsev, 1986). Due to the magnetosphere-ionosphere interaction, the arc velocity should be somewhat slower than the convection velocity (Kozlovsky and Lyatsky, 1994). Thus, the interchange instability can explain well the observed characteristics of the high-latitude arcs: originating from the region of nightside activity, fast sunward propagation along the auroral oval, and 
the northward drift with the convection velocity.

The multiple arc events made up a significant part of our data set. As mentioned above, the multiple arcs are a feature of the post-noon and pre-noon auroras (Sandholt et al., 1998). It is interesting that one of the possible reasons for "sun-aligned" arcs in the morning sector mentioned by Shiokawa et al. (1997) is the substorm activity in the night. In the view of our results, we can suppose that the interchange instability starting in the nightside magnetosphere may give rise to the arcs, which expand to dawn and/or dusk and are referred to as post-noon and pre-noon multiple auroras or "sunaligned" arcs.

\section{Conclusions}

The azimuthal expansion of the high-latitude auroral arcs has been investigated, together with the ionospheric convection measurements and the auroral oval imaging. We considered the events, for which propagation of the westward or eastward end of the arc was clearly identified in the TV frames. The main findings of our study are the following:

1. The high-latitude arcs propagate westward in the premidnight sector and eastward in the post-midnight sector. The arc expansion corresponds to their expansion from the active auroras, like the auroral bulge or WTS observed around the midnight.

2. The arcs propagate along their stretching in the same direction as the background convection flow at the velocity of $2-3 \mathrm{kms}^{-1}$, which was $1-2 \mathrm{kms}^{-1}$ faster than the convection velocity measured in the arc vicinity.

3. The arcs drifted pole- or equatorward at the velocity of the order of $100 \mathrm{~m} / \mathrm{s}$ that was close to the convection velocity in the same direction.

These experimental results can be well explained in terms of the interchange (or flute) instability.

Acknowledgements. We thank A. Roldugin (PGI) for the BAB TV data of good quality, N. Safargaleeva (PGI Data Center) for the assistance in the TV data selection and O. Troshichev (AARI) for the DIK magnetic data. We thank also Prof. Mark Lester and Dr. Steve Milan for the CUTLASS data. CUTLASS is a PPARC facility deployed and operated by the University of Leicester in conjuction with the Finish Meteorlogical Institute, Helsinki and the Institute for Space Physics, Uppsala. The POLAR UVI, POLAR VIS, and Hankasalmi radar data were obtained through CDAWeb (the data providers are L. Frank at the University of Iowa, G. Parks at the University of Washington, and R. Greenwald at JHU/APL). The LYR magnetic station is a part of the IMAGE system. The DMSP particle detectors were designed by Dave Hardy of AFRL, and data obtained from JHU/APL. We thank Dave Hardy, Fred Rich, and Patrick Newell for its use. The DMSP visible images were obtained through SPIDR. The used keograms were obtained from the web page of the Geophysical Research Division of Finnish Meteorological Institute (http://www.geo.fmi.fi/) operating the all-sky camera network in Northen Scandinavia. The work by S. Osipenko was supported by the Grant for Young Scientists (SPbU) No. M01-2.7K258. A part of investigation was made during the visit of V.S. to Oulu University. The work of A. K. was supported by the Finnish Academy of Science and Letters Vilho, Yrjö and Kalle Väisälä Foundation.

Topical Editor M. Lester thanks K. Shiokawa and S. Murphree for their help in evaluating this paper.

\section{References}

Atkinson, G.: Decoupling of convection in the magnetosphere from the ionosphere by parallel electric fields, AGU Fall Meeting 2001, abstract No SM51A-0784, AGU, 2001.

Borovsky, J. R.: Auroral arc thickness as predicted by various theories, J. Geophys. Res., 98, 6101-6138, 1993.

Borovsky, J. E., Thomsen, M. F., Elphic, R. C., Cayton, T. E., and McComas, D. J.: The transport of plasma sheet material from the distant tail to geosynchronous orbit, J. Geophys. Res., 103, 20 297-20 332, 1998.

Danielides, M. A. and Kozlovsky, A.: Rocket-born investigation of auroral patches in the evening sector during substorm recovery, Ann. Geophysicae, 21, 719-728, 2003.

Feldstein, Y. I. and Starkov, G. V.: Dynamics of auroral belt and polar geomagnetic disturbances, Planet. Space Sci., 16, 209-230, 1967.

Haerendel, G., Buchert, S., La Hoz, C., Raaf, B., and Rieger, E.: On the proper motion of auroral arcs, J. Geophys. Res., 98, 60876099, 1993.

Kadomtsev, B. B.: Cooperative Effects in Plasmas, 304 pp., Nauka, Moscow, 1988.

Kamide, Y. and Rostoker, G.: The spatial relationship of field aligned currents and auroral electrojets to the distribution of nighside auroras, J. Geophys. Res., 82, 5589-5608, 1977.

Kan, J. R., Deer, C. S., Lyu, L. H., and Newell, P. T.: Ionospheric signatures of patchy intermitted reconnection at dayside magnetopause, J. Geophys. Res., 101, 10 939-10 945, 1996.

Kozlovsky, A. E. and Lyatsky, W. B.: Instability of the magnetosphere-ionosphere convection and formation of auroral arcs, Ann. Geophysicae, 12, 636-641, 1994.

Kozlovsky, A., Lakkala, T., Kangas, J., and Aikio, A.: Response of the quiet auroral arc motion to ionospheric convection variations, J. Geophys. Res., 106, 21 463-21 474, 2001.

Kozlovsky, A. and Kangas, J.: Motion and origin of noon highlatitude poleward moving auroral arcs on closed magnetic field lines, J. Geophys. Res., 107(2), 10.1029/2001JA900145, 2002.

Lyatsky, W. B.: On the effect of modified interchange instability on substorm development, Poceedings of the First International Conference on Substorms, Kiruna, Sweden, (ESA SP-335), 329331, 1992.

Moen, J., Burke, W. J., and Sandholt, P. E.: A rotating, midday auroral event with northward interplanetary magnetic field, J. Geophys. Res., 98, 13 731-13 739, 1993.

Newell, P. T., Feldstein, Y. I., Galperin, Y. I., and Meng, C.-I.: Morphology of nightside precipitation, J. Geophys. Res., 101, 10737-10 749, 1996.

Nielsen E., Elphinstone, R. D., Hearn, D. J., et al.: Oval intensification event observed by STARE and Viking, J. Geophys. Res., 98, 6163-6171, 1993.

Nilsson, H., Yamauchi, M., Mukai, T., Yamamoto, T., and Moretto, T.: Observations of enhanced convection flow channel for northward turning IMF, Geophys. Res. Lett., 24, 3137-3140, 1997. 
Oguti, T.: Rotational deformations and related drift motions of auroral arcs, J. Geophys. Res., 79, 3861-3865, 1974.

Opgenoorth, H. J., Pellinen, R. J., Baumjohann, W., et al.: Threedimensional current flow and particle precipitation in a westward traveling surge (observed during the barium-GEOS rocket experiment), J. Geophys. Res., 88, 3138, 1983.

Rezhenov B. V.: A possible mechanism for $\theta$ aurora formation, Ann. Geophysicae, 13, 698-703, 1995.

Rostoker, G., Lui, A. T. Y., Anger, C. D., and Murphree, J. S.: North-south structures in the midnight sector auroras as viewd by the Viking imager, Geophys. Res. Lett., 14, 407-410, 1987.

Ruohoniemi, J. M., Greenwald, R. A., Baker, K. B., Villain, J.-P., Hanuise, C., and Kelly, J.: Mapping high-latitude plasma convection with coherent HF radars, J. Geophys. Res., 94, $13463-$ $13477,1989$.

Safargaleev, V. V. and Osipenko, S. V.: Precursors of magnetospheric substorm in pulsating and diffuse auroras, Geomagn. Aeronomy, 41, 791-797, (in Russian), 2001.

Sandholt, P. E., Lokwood, M., Oguti, T., Cowley, S. W., Freeman, K. S. C., Lybekk, D., Egeland, A., and Willis, D. M.: Midday auroral breakup events and related energy and momentum transfer from the magnetosheath, J. Geophys. Res., 95, 1039, 1990.

Sandholt, P. E., C. J. Farrugia, J. Moen, Noraberg,Ø., Lybekk, B., Sten, T., and Hansen, T.: A classification of dayside auroral forms and activities as a function of interplanetary magnetic field orientation, J. Geophys. Res., 103, 23 325-23 345, 1998.

Shiokawa, K. T., Ogino, T., Hayashi, K., and McEven, D. J.: Quasiperiodic poleward motion of morningside sun-aligned arcs: A multievent study, J. Geophys. Res., 102, 24 325-24 332, 1997.

Snyder, A. and Akasofu, S.-I.: Observations of the auroral oval by the Alaskan meridian chain of stations, J. Geophys. Res., 77, 3419-3430, 1972.

Starkov, G. V.: Auroral heights in the polar cap, Geomagn. Aeron., Engl. Transl., 8, 28-32, 1968.

Swift, D. W.: The possible relationship between the auroral breakup and the interchange instability of the ring current, Planet. Space Sci., 15, 1225-1238, 1967.

Swift, D. W.: Mechanisms for auroral precipitation: A review, Rev. Geophys. Space Phys., 19, 185-211, 1981.

Volkov, M. A. and Maltsev, Y. P.: Interchange instability of the inner plasma sheet boundary, Geomagn. Aeronomy, 26, 798-801 (in Russian), 1986.

Yahnin, A. G., Sergeev, V. A., Pellinen, R. J., Baumjohann, W., et al.: Substorm time sequence and microstructure on 11 November 1976, J. Geophys., 53, 182, 1983.

Yamamoto, T., Inoue, S., Nishitani, N., Ozaki, M., and Meng, C.-I.: A theory for generation of the paired region 1 and region 2 fieldaligned currents, J. Geophys. Res., 101, 27 199-27 222, 1996. 